\title{
Morphological Study of Root Canals of Maxillary Molars by Cone-Beam Computed Tomography
}

\author{
Jackeline Magalhães (D), ${ }^{1}$ Christianne Velozo $\left(\mathbb{D},{ }^{2}\right.$ Diana Albuquerque $\mathbb{D}^{1},{ }^{2}$ Caio Soares, \\ Hugo Oliveira, ${ }^{1}$ Maria Luíza Pontual, ${ }^{1}$ Flávia Ramos-Perez, ${ }^{1}$ and Andrea Pontual ${ }^{1}$ \\ ${ }^{1}$ Department of Clinical and Preventive Dentistry, Federal University of Pernambuco, Recife, PE, Brazil \\ ${ }^{2}$ Department of Restorative Dentistry and Endodontics, Dental College of Pernambuco, University of Pernambuco, \\ Recife, PE, Brazil
}

Correspondence should be addressed to Christianne Velozo; chris_velozo@hotmail.com

Received 16 November 2021; Accepted 4 January 2022; Published 18 January 2022

Academic Editor: Carlo Eduardo Medina-Solis

Copyright (c) 2022 Jackeline Magalhães et al. This is an open access article distributed under the Creative Commons Attribution License, which permits unrestricted use, distribution, and reproduction in any medium, provided the original work is properly cited.

\begin{abstract}
The aim of this study was to evaluate the root canal morphology of permanent maxillary molars by cone-beam computed tomography (CBCT) using the classifications of Weine et al. and Vertucci and to correlate the findings with sex, age, position in the dental arch, and prevalence of a second canal in the mesiobuccal root (MB2). A total of 414 scans were evaluated, corresponding to 1,000 teeth. The assessment consisted of coronal, axial, and sagittal reconstructions using i-CAT Workstation ${ }^{\circledR}$. Type 0 was assigned when neither classification could be applied. The data were entered into an Excel spreadsheet and analyzed using SPSS. The chisquared test or Fisher's exact test was used to compare the distribution of root canal morphology classified using the two systems. Analysis of the distribution of Weine types showed a predominance of type III in mesiobuccal roots, while type 0 predominated in distobuccal and palatal roots. Vertucci type IV predominated in mesiobuccal and distobuccal roots and type VII in palatal roots. There was no difference in the distribution of morphological canal types in permanent maxillary molars evaluated by CBCT according to sex, age group, or position in the dental arch of the patients. MB2 canals were identified in $68.4 \%$ of the teeth evaluated.
\end{abstract}

\section{Introduction}

The main objective of endodontic treatment is the cleaning, disinfection, and three-dimensional filling of the root canal system in order to prevent reinfection and to cure the infection [1]. Improvements in endodontic treatment have been achieved over the past decades by the development of new materials, techniques, and devices in order to increase success rates [2]. However, the success of this treatment depends on accurate knowledge about the morphology of root canals, which is very complex due to the splitting and union of canals during their trajectory [3].

Root canal morphology shows distinct configurations between different populations and between different tooth groups, particularly among molars [3]. The maxillary molars have complex anatomy, and their root canal system is characterized by wide variations, a fact that represents a constant challenge for the dentist [4]. These teeth generally have three roots (mesiobuccal (MB), distobuccal (DB), and palatal $(\mathrm{P})$ ) and can contain up to three mesial canals, two distal canals, and two palatal canals $[5,6]$. In addition, the $\mathrm{MB}$ root can contain a second root canal system (MB2) that can range from a single to multiple canals [7].

The main causes of endodontic treatment failure include incomplete fillings and the presence of untreated root canals and thus result in the persistence of microorganisms in intact areas that become inaccessible and incompletely filled, leading to the failure of endodontic treatment $[2,8,9]$. The lack of knowledge of root canal morphology can compromise the identification of additional canals and contribute to this failure. Knowledge of the anatomical variations of root canals is therefore essential in order to avoid undesirable failures and to increase the chances of successful endodontic treatment $[3,10]$. 
Periapical radiographs continue to be the most widely used images for root canal assessment during endodontic treatment that can provide useful information for the clinician. Despite their widespread use, these images provide limited information about morphological variations, neighboring bone densities, X-ray angulations and contrast, and factors that can influence radiographic interpretation [11]. The absence of three-dimensional information and the presence of areas of interest masked by overlapping structures in the images interfere with the establishment of the correct diagnosis [12].

In endodontics, cone-beam computed tomography (CBCT) has been shown to be very useful in assessing the morphology and location of the root canal, as well as in the visualization of the root's anatomy, differential diagnosis between endodontic and nonendodontic pathologies, evaluation of alveolar and root fractures, analysis of internal and external resorption, presurgical endodontic planning, evaluation of root preparation, obturation, retreatment, detection of bone lesions, and endodontic research [11]. Since CBCT provides an in-depth view of the morphology of the root canal, this technique may be indicated to obtain information on complex anatomies [13].

The aim of the present study was to evaluate the root canal morphology of permanent maxillary molars by CBCT and its correlation with sex, age, position (right/left) in the dental arch, and the prevalence of MB2.

\section{Materials and Methods}

2.1. Ethical Aspects. The study was approved by the Ethics Committee of the Federal University of Pernambuco (approval number 2.224.057) and was conducted in accordance with the ethical guidelines of Resolution $466 / 12$ of the National Health Council that regulates research involving humans.

2.2. Sample. The study was conducted at the Dental Radiology Clinic, Federal University of Pernambuco, Recife, Pernambuco, Brazil, in a dark room to optimize visualization of the root canal anatomy.

All maxillary CBCT scans of patients seen between January 2016 and January 2017 at a private dental radiology service were retrieved. Only scans that met the predefined inclusion and exclusion criteria were selected for the sample of the present study.

2.3. Cone-Beam Computed Tomography. The scans were acquired with the i-CAT Next Generation ${ }^{\circledR}$ CBCT scanner (Imaging Sciences International, Hatfield, Pennsylvania, USA) that provides volumetric data within a few seconds. This device uses a fixed voltage and current of $120 \mathrm{kVp}$ and $5.5 \mathrm{~mA}$, respectively, and a focal spot size of $0.5 \mathrm{~mm}$. The digital image detector is composed of a $20 \times 25 \mathrm{~cm}$ flat amorphous silicon plate. For this study, the image was captured with 14 bits of resolution and a voxel pixel of 0.3 / 0.3 by the same operator. The image was acquired in a single
360 -degree rotation around the patient. The scan volume is $17 \mathrm{~cm}$ in diameter by $13 \mathrm{~cm}$ in height.

For acquisition of the CBCT images, the patient was positioned in the device in such a way that the occlusal plane remained parallel to the ground, following the image acquisition protocol recommended by the manufacturer. After the acquisition, the images appear on the computer screen within a few seconds and are stored in xstd format (xoran extension) for subsequent evaluation.

2.4. Inclusion and Exclusion Criteria. Scans of patients ranging in age from 10 to 90 years with permanent maxillary first and/or second molars were included in the study.

CBCT scans of the maxilla showing maxillary first and/or second molars with endodontic treatment, extensive caries, incomplete rhizogenesis, fused roots, root remnants, and image artifacts resulting from dental implants in adjacent teeth were excluded. CBCT scans of the maxilla without adequate diagnostic quality and scans of the mandible were also not included in the study.

2.5. Calibration. The tomographic images were evaluated by an examiner who had been previously trained and calibrated in the proposed assessment using this imaging modality. Calibration consisted of assessing tomographic images from 30 teeth (maxillary first and second molars), selected according to the predefined inclusion and exclusion criteria, under the same established conditions. These teeth were evaluated and reevaluated after one week to determine intraexaminer agreement for the morphological types attributed to the root canals according to the classifications of Weine et al. [14] and Vertucci [15]. The data obtained were entered into an Excel $^{\circledR}$ spreadsheet (Microsoft Corporation, Redmond, Washington, USA) and then transferred to the SPSS software (Statistical Package for the Social Sciences ${ }^{\circledR}$ version 20). Intraexaminer reliability was evaluated using Cohen's kappa test. Calibration was performed, and a satisfactory kappa index was obtained (good to perfect classification).

2.6. Selection of Sample. A total of 840 CBCT scans from the database performed for different reasons were examined. Of these, 426 scans were not included in the assessment because of (1) insufficient field of view, (2) presence of at least one of the exclusion criteria attributed to all maxillary molars, and (3) poor image quality for diagnostic purposes. Among all maxillary scans examined, 1,350 teeth were excluded from the sample because they met one or more of the predefined exclusion criteria. The sample consisted of 414 maxillary scans, including 238 female patients and 176 male patients ranging in age from 10 to 89 years. A total of 1,000 teeth were evaluated: 505 on the right side and 495 on the left side (Table 1).

2.7. Evaluation of the CBCT Images. The root canal morphology of the molars was evaluated in a dark and silent room at the Dental Radiology Clinic of UFPE using a 
TABLE 1: Scans excluded from the sample, maxillary teeth excluded and included from the sample

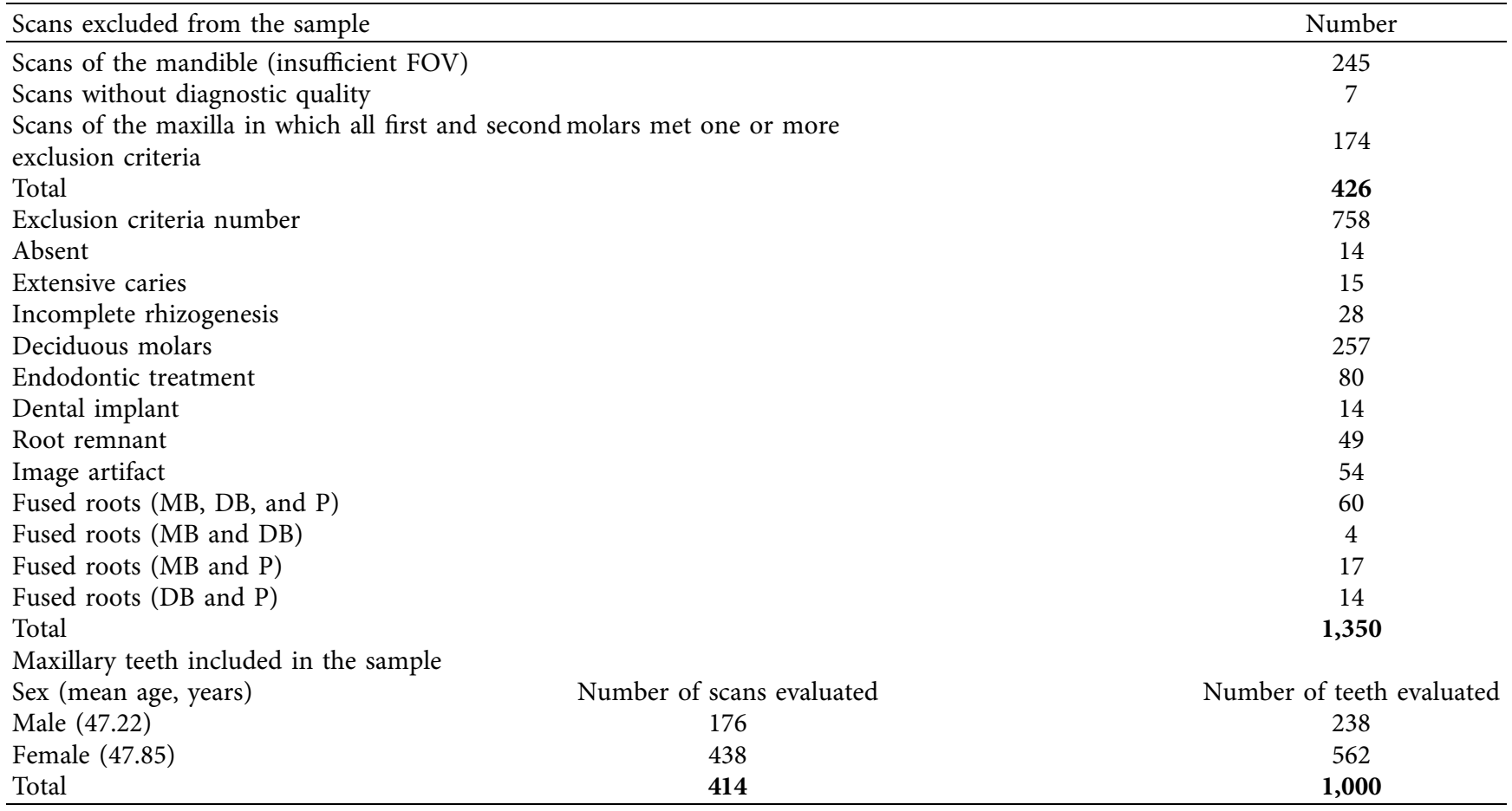

MB: mesiobuccal; DB: distobuccal; P: palatal.

computer with a $22^{\prime \prime}$ monitor and i-CAT Workstation ${ }^{\circledR}$ (Imaging Sciences International, Pennsylvania, USA). The interface of the program was used to evaluate the root canals in coronal, axial, and sagittal sections.

In the window of axial sections, the examiner determined the section where the long axis of the tooth, first or second molar, had the largest diameter, visualized in its long axis, and the examiner determined the central sagittal section. Through this window of sections, the volume was rotated in order to align the long axis of the tooth with the vertical plane.

Prior to the assessment, the images were processed using the same filter (sharpness, brightness, and contrast) in order to enable better visualization and standardization of the reconstructions. Next, the morphology of the root canals was classified according to Weine et al. [14] and Vertucci [15] (Table 2 and Figures 1-4), the classifications most commonly used in the literature. In addition to the classification of root canal morphology, the presence of MB2 canals in the maxillary molars was evaluated. For statistical purposes, type 0 was assigned to cases that did not meet the criteria of either classification.

2.8. Data Analysis. The data of the tomographic assessments were entered into an Excel $^{\circledR}$ spreadsheet (Microsoft Corporation, Redmond, Washington, USA), including patient age and sex and tooth and type of internal root canal configuration according to the two anatomical classifications used, for subsequent statistical analysis. A database was built in SPSS 20 (Statistical Package for the Social Sciences) for analysis of the data. The chi-squared test for homogeneity was applied to compare the distribution of root canal morphology classified according to Weine et al. [14] and Vertucci [15] among sexes, age groups, and sides of the dental arches of the patients evaluated. When the assumptions of the chi-squared test were not met, Fisher's exact test was applied. For statistical analysis, the following age categories were established: children and teenagers ( 0 to 17 years), adults (18 to 65 years), middle-aged adults (66 to 79 years), and older adults (80 to 99 years). A level of significance of $5 \%$ was adopted.

\section{Results and Discussion}

In the present study, type 0 was attributed to teeth whose root canal morphology could not be classified according to the criteria of Weine et al. [14].

The prevalence of the morphological canal types according to the classification of Weine et al. [14] and Vertucci [15] found in the total sample is shown in Table 3.

Table 4 shows the distribution of Weine canal types for $\mathrm{MB}, \mathrm{DB}$, and palatal roots, respectively, according to sex, age group, and dental arch of the patient evaluated.

Table 5 shows the distribution of Vertucci canal types for $\mathrm{MB}, \mathrm{DB}$, and palatal roots, respectively, according to sex, age group, and dental arch of the patient evaluated.

The distribution of MB2 canals in the sample studied according to sex, age group, and dental arch is shown in Table 6.

The present study showed marked anatomical variations in the root canal morphology of maxillary molars. Knowing that anatomical features influence the success of endodontic treatment, dentists must be aware of these anatomical 
TABle 2: Classification of the root canal system proposed by Weine et al. [14] and Vertucci [15].

Morphological type by Weine et al. [14]

Type I

Type II

Type III

Type IV

Morphological type by Vertucci

[15]

Type I

Type II

Type III

Type IV

Type V

Type VI

Type VII

Type VIII

\section{Description}

Single canal from the pulp chamber to the apex.

Two separate canals leave the pulp chamber and join short of the apex to form one canal.

Two separate and distinct canals from the pulp chamber to the apex.

A single canal leaves the pulp chamber and divides into two canals with two separate foramina.

\section{Description}

A single canal extending from the pulp chamber to the apex.

Two canals leave the pulp chamber and join short of the apex to form a single canal. A single canal leaves the pulp chamber, divides into two inside the root, and then merges to form one canal.

Two separate and distinct canals extending from the pulp chamber to the apex. A single canal leaves the pulp chamber and divides into two canals with separate apical foramina. Two separate canals leave the pulp chamber, merge in the body of the root, and redivide short of the apex to exit as two distinct canals.

A single canal leaves the pulp chamber, divides into two canals that then merge in the middle third of the root, and finally redivide into two distinct canals short of the apex. Three separate canals extending from the pulp chamber to the apex.

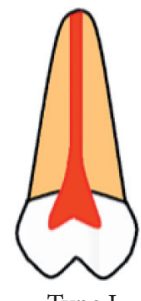

Type I

(1)

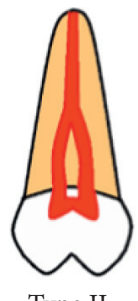

$(2-1)$

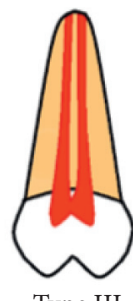

Type III

(2)

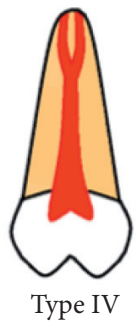

(1-2)

Figure 1: Illustrative image of the morphological classification of root canals according to Weine et al. [14].

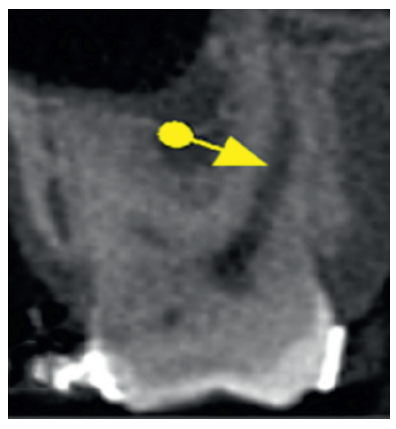

(a)

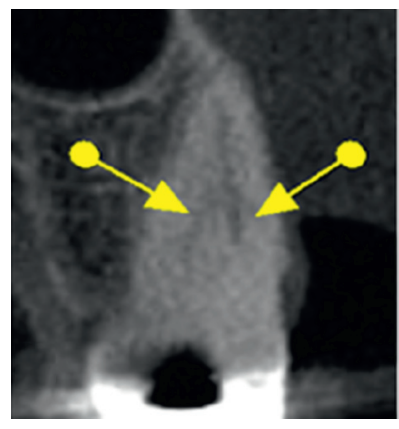

(b)

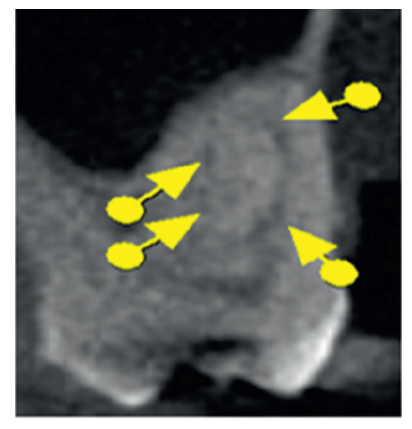

(c)

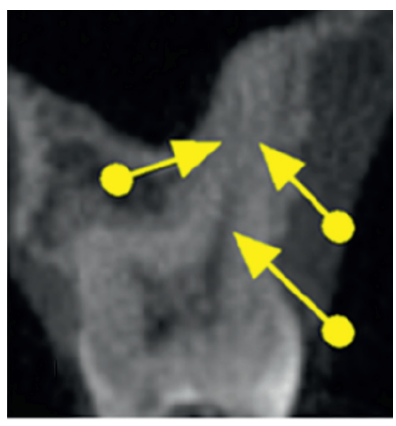

(d)

Figure 2: Coronal sections showing the different morphological types proposed by Weine et al. [14], (a) type I, (b) type II, (c) type III, and (d) type IV.

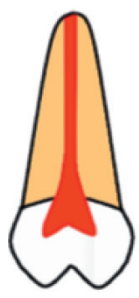

Type I

(1)

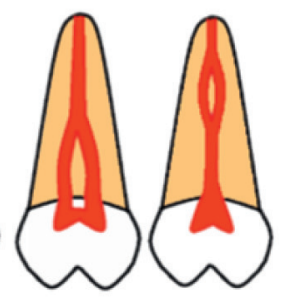

Type II

(2-1)

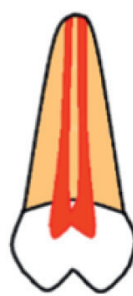

Type IV

(2)

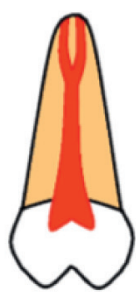

Type V

(1-2)

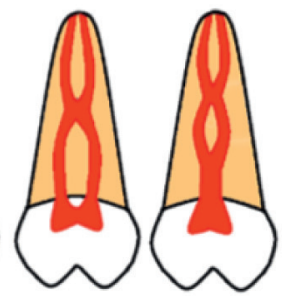

Type VI

(2-1-2)
Type VII (1-2-1-2)

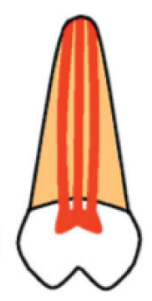

Type VIII

(3)

FIGURE 3: Illustrative image of the morphological classification of root canals according to Vertucci [15]. 


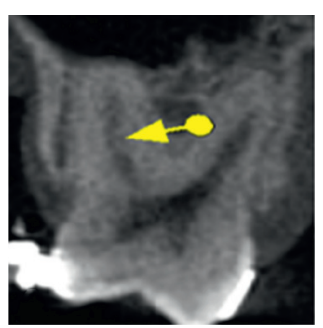

(a)

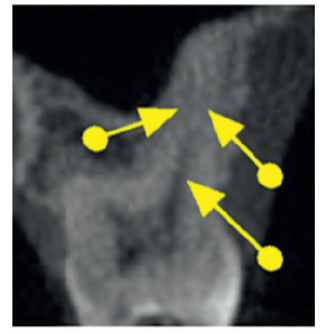

(e)

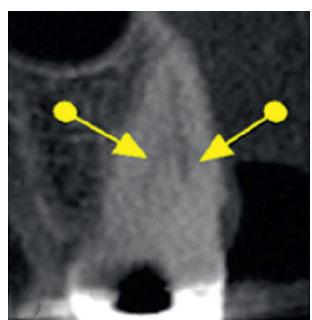

(b)

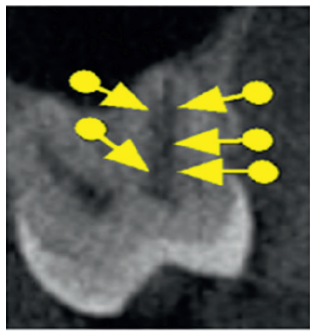

(f)

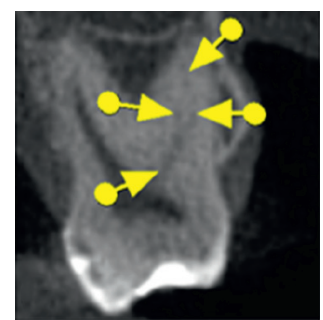

(c)

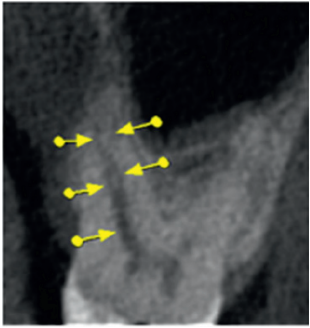

(g)

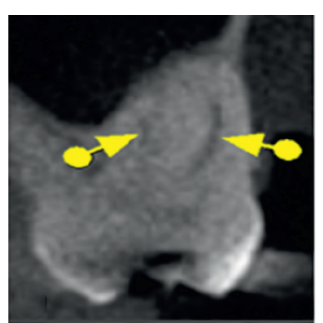

(d)

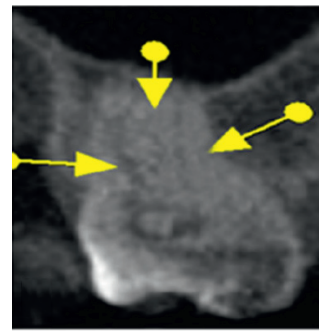

(h)

FIGURE 4: Coronal sections showing the different morphological types proposed by Vertucci [15]: (a) type I, (b) type II, (c) type III, (d) type IV, (e) type V, (f) type VI, (g) type VII, and (h) type VIII.

TABle 3: Prevalence of morphological root canal types according to the classifications proposed by Weine et al. [14] and Vertucci [15].

\begin{tabular}{|c|c|c|c|}
\hline Classification & $\begin{array}{c}\text { Mesiobuccal } \\
\text { Prevalence (\%) }\end{array}$ & $\begin{array}{c}\text { Distobuccal } \\
\text { Prevalence (\%) }\end{array}$ & $\begin{array}{c}\text { Palatal } \\
\text { Prevalence }(\%)\end{array}$ \\
\hline \multicolumn{4}{|c|}{ Weine et al. [14] } \\
\hline Type 0 & $\begin{array}{c}304 \\
(30.4) \\
\end{array}$ & $\begin{array}{c}602 \\
(60.2) \\
\end{array}$ & $\begin{array}{c}605 \\
(60.5) \\
\end{array}$ \\
\hline Type I & $\begin{array}{c}2 \\
(0.2) \\
\end{array}$ & $\begin{array}{c}43 \\
(4.3) \\
\end{array}$ & $\begin{array}{c}266 \\
(26.6) \\
\end{array}$ \\
\hline Type II & $\begin{array}{c}9 \\
(0.9) \\
\end{array}$ & $\begin{array}{c}4 \\
(0.4) \\
\end{array}$ & $\begin{array}{c}17 \\
(1.7) \\
\end{array}$ \\
\hline Type III & $\begin{array}{c}684 \\
(68.4)\end{array}$ & $\begin{array}{c}344 \\
(34.4)\end{array}$ & $\begin{array}{c}94 \\
(9.4)\end{array}$ \\
\hline Type IV & $\begin{array}{c}1 \\
(0.1)\end{array}$ & $\begin{array}{c}7 \\
(0.7)\end{array}$ & $\begin{array}{c}18 \\
(1.8)\end{array}$ \\
\hline \multicolumn{4}{|l|}{ Vertucci [15] } \\
\hline Type I & $\begin{array}{c}2 \\
(0.2) \\
\end{array}$ & $\begin{array}{c}43 \\
(4.3) \\
\end{array}$ & $\begin{array}{c}266 \\
(26.6) \\
\end{array}$ \\
\hline Type II & $\begin{array}{c}9 \\
(0.9) \\
\end{array}$ & $\begin{array}{c}4 \\
(0.4) \\
\end{array}$ & $\begin{array}{c}17 \\
(1.7) \\
\end{array}$ \\
\hline Type III & $\begin{array}{c}12 \\
(1.2) \\
\end{array}$ & $\begin{array}{l}50 \\
(5) \\
\end{array}$ & $\begin{array}{l}160 \\
(16) \\
\end{array}$ \\
\hline Type IV & $\begin{array}{c}684 \\
(68.4) \\
\end{array}$ & $\begin{array}{c}345 \\
(34.5) \\
\end{array}$ & $\begin{array}{c}92 \\
(9.2) \\
\end{array}$ \\
\hline Type V & $\begin{array}{c}1 \\
(0.1) \\
\end{array}$ & $\begin{array}{c}7 \\
(0.7) \\
\end{array}$ & $\begin{array}{c}18 \\
(1.8) \\
\end{array}$ \\
\hline Type VI & $\begin{array}{c}83 \\
(8.3) \\
\end{array}$ & $\begin{array}{l}260 \\
(26)\end{array}$ & $\begin{array}{c}133 \\
(13.3)\end{array}$ \\
\hline Type VII & $\begin{array}{c}29 \\
(2.9) \\
\end{array}$ & $\begin{array}{c}247 \\
(24.7) \\
\end{array}$ & $\begin{array}{c}291 \\
(29.1) \\
\end{array}$ \\
\hline Type VIII & $\begin{array}{l}180 \\
(18) \\
\end{array}$ & $\begin{array}{c}44 \\
(4.4) \\
\end{array}$ & $\begin{array}{c}23 \\
(2.3) \\
\end{array}$ \\
\hline
\end{tabular}


TABLE 4: Distribution of the different morphological types proposed by Weine et al. [14] for mesiobuccal roots, distobuccal roots, and palatal roots according to sex, age group, and dental arch of the patient evaluated.

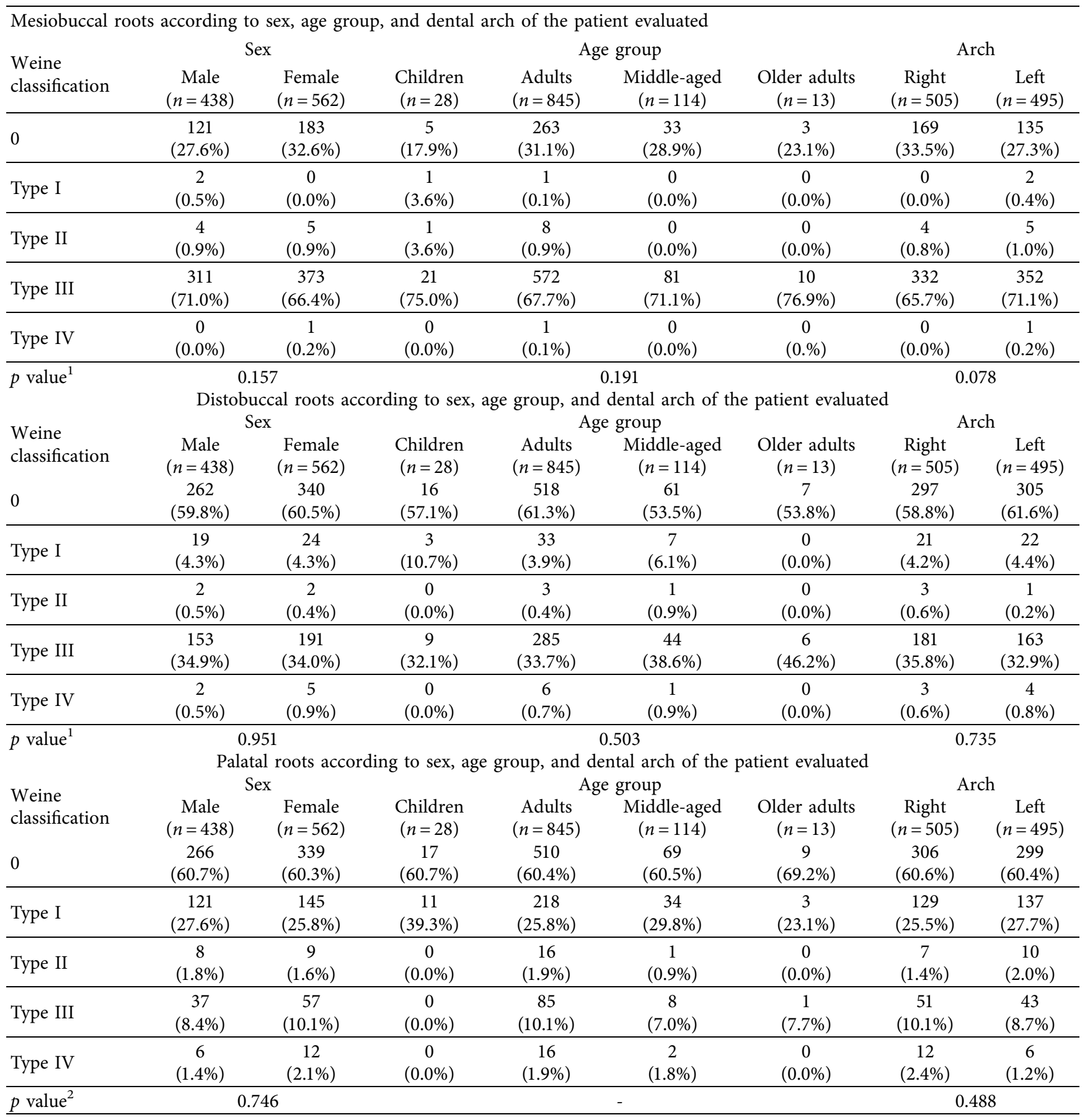

${ }^{1}$ Fisher's exact test; ${ }^{2}$ chi-squared test for homogeneity.

complexities since inadequate knowledge can result in untreated canals and root canal perforations or transportation [16].

Using the classification proposed by Weine et al. [14], we observed a higher prevalence of canal morphology type III in $\mathrm{MB}$ roots of maxillary molars. Similar results have been reported by others CBCT studies [17, 18]. In contrast, another study [19] that evaluated root canals under a surgical microscope found Weine type I to be the most prevalent in $\mathrm{MB}$ roots, followed by type III.

The root canal morphology of 812 maxillary first and second molars in a Greek population by CBCT using the classification of Weine et al. [14] was evaluated, and type III was the most prevalent in MB roots [20], in agreement with the present results. However, in DB and $\mathrm{P}$ roots, the authors found a predominance of type I [20]. As observed in the 
TABLE 5: Distribution of the different morphological types proposed by Vertucci [15] for mesiobuccal roots, distobuccal roots, and palatal roots according to sex, age group, and dental arch of the patient evaluated.

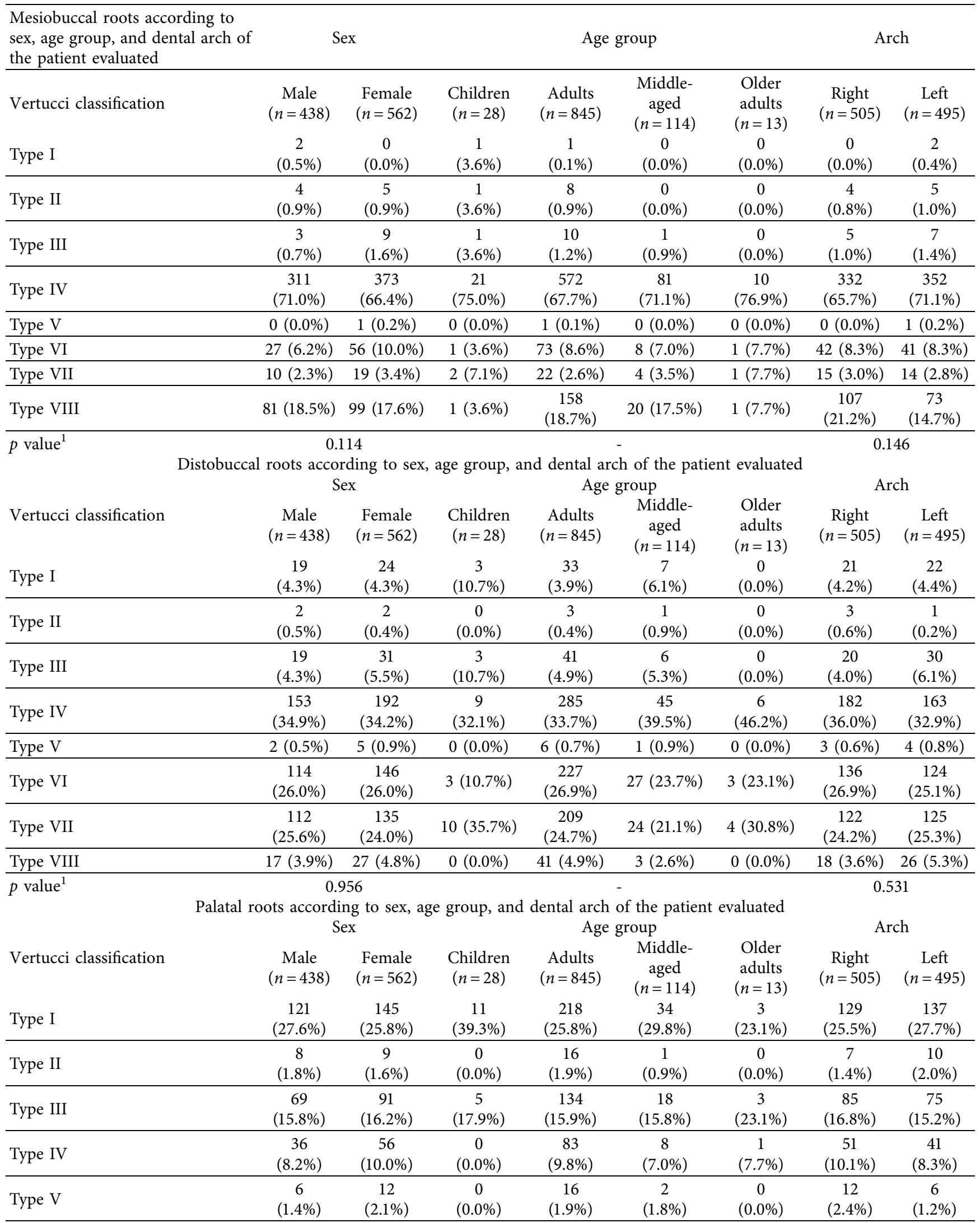


TABLE 5: Continued.

\begin{tabular}{|c|c|c|c|c|c|c|c|c|}
\hline $\begin{array}{l}\text { Mesiobuccal roots according to } \\
\text { sex, age group, and dental arch of }\end{array}$ & \multicolumn{2}{|c|}{ Sex } & \multicolumn{4}{|c|}{ Age group } & \multicolumn{2}{|c|}{ Arch } \\
\hline Type VI & $\begin{array}{c}56 \\
(12.8 \%) \\
\end{array}$ & $\begin{array}{c}77 \\
(13.7 \%) \\
\end{array}$ & $\begin{array}{c}4 \\
(14.3 \%) \\
\end{array}$ & $\begin{array}{c}111 \\
(13.1 \%) \\
\end{array}$ & $\begin{array}{c}15 \\
(13.2 \%) \\
\end{array}$ & $\begin{array}{c}3 \\
(23.1 \%) \\
\end{array}$ & $\begin{array}{c}58 \\
(11.5 \%) \\
\end{array}$ & $\begin{array}{c}75 \\
(15.2 \%) \\
\end{array}$ \\
\hline Type VII & $\begin{array}{c}132 \\
(30.1 \%)\end{array}$ & $\begin{array}{c}159 \\
(28.3 \%) \\
\end{array}$ & $\begin{array}{c}8 \\
(28.6 \%) \\
\end{array}$ & $\begin{array}{c}245 \\
(29.0 \%) \\
\end{array}$ & $\begin{array}{c}35 \\
(30.7 \%) \\
\end{array}$ & $\begin{array}{c}3 \\
(23.1 \%) \\
\end{array}$ & $\begin{array}{c}150 \\
(29.7 \%)\end{array}$ & $\begin{array}{c}141 \\
(28.5 \%)\end{array}$ \\
\hline Type VIII & $\begin{array}{c}10 \\
(2.3 \%) \\
\end{array}$ & $\begin{array}{c}13 \\
(2.3 \%) \\
\end{array}$ & $\begin{array}{c}0 \\
(0.0 \%) \\
\end{array}$ & $\begin{array}{c}22 \\
(2.6 \%) \\
\end{array}$ & $\begin{array}{c}1 \\
(0.9 \%) \\
\end{array}$ & $\begin{array}{c}0 \\
(0.0 \%) \\
\end{array}$ & $\begin{array}{c}13 \\
(2.6 \%) \\
\end{array}$ & $\begin{array}{c}10 \\
(2.0 \%)\end{array}$ \\
\hline$p$ value $^{2}$ & \multicolumn{2}{|c|}{0.929} & & \multicolumn{2}{|c|}{-} & & \multicolumn{2}{|c|}{0.406} \\
\hline
\end{tabular}

${ }^{1}$ Fisher's exact test; ${ }^{2}$ chi-squared test for homogeneity.

TABle 6: Prevalence of a second canal in the mesiobuccal root (MB2) according to sex, age group, and dental arch of the patient evaluated.

\begin{tabular}{|c|c|c|c|c|c|c|c|c|}
\hline & \multicolumn{2}{|c|}{ Sex } & \multicolumn{4}{|c|}{ Age group } & \multicolumn{2}{|c|}{ Arch } \\
\hline & $\begin{array}{c}\text { Male } \\
(n=438)\end{array}$ & $\begin{array}{c}\text { Female } \\
(n=562)\end{array}$ & $\begin{array}{l}\text { Children } \\
(n=28)\end{array}$ & $\begin{array}{c}\text { Adults } \\
(n=845)\end{array}$ & $\begin{array}{c}\text { Middle-aged } \\
\quad(n=114)\end{array}$ & $\begin{array}{l}\text { Older adults } \\
(n=13)\end{array}$ & $\begin{array}{c}\text { Right } \\
(n=505)\end{array}$ & $\begin{array}{c}\text { Left } \\
(n=495) \\
\end{array}$ \\
\hline MB2 & $\begin{array}{c}311 \\
(71.0 \%)\end{array}$ & $\begin{array}{c}373 \\
(66.4 \%)\end{array}$ & $\begin{array}{c}21 \\
(75.0 \%)\end{array}$ & $\begin{array}{c}572 \\
(67.7 \%)\end{array}$ & $\begin{array}{c}81 \\
(71.1 \%)\end{array}$ & $\begin{array}{c}10 \\
(76.9 \%)\end{array}$ & $\begin{array}{c}332 \\
(65.7 \%)\end{array}$ & $\begin{array}{c}352 \\
(71.1 \%)\end{array}$ \\
\hline $\begin{array}{l}p \\
\text { value }^{1}\end{array}$ & \multicolumn{2}{|c|}{0.157} & \multicolumn{4}{|c|}{0.191} & \multicolumn{2}{|c|}{0.078} \\
\hline
\end{tabular}

${ }^{1}$ Fisher's exact test.

present study, there were no significant differences in morphological canal types between sexes.

The anatomy of $\mathrm{MB}, \mathrm{DB}$, and $\mathrm{P}$ root canals of 442 maxillary molars in a Ugandan population using a clearing technique was analyzed, and the authors [21] found Weine type I to be the most prevalent morphology in all roots. These results differ from the present study in which type III predominated in $\mathrm{MB}$ roots and type 0 (root canals that could not be classified) in DB and $\mathrm{P}$ roots. The differences between the results reported by these authors and the present findings might be explained by the method used for the evaluation of root canal morphology. In addition, the divergences may also be attributed to the assessment criteria established, population differences, inclusion/exclusion criteria, or the small sample size when compared to the present study.

In the present study, using the classification proposed by Vertucci [15], the most prevalent morphological types found in $\mathrm{MB}, \mathrm{DB}$, and $\mathrm{P}$ roots were types IV, IV, and VII, respectively. In contrast, others authors obtained divergent results using cleared teeth and reported a higher prevalence of morphological types $\mathrm{II}, \mathrm{I}$, and $\mathrm{I}$ in $\mathrm{MB}, \mathrm{DB}$, and $\mathrm{P}$ roots, respectively [22].

In another study [23], types II, III, and IV were the most common morphological types in $\mathrm{MB}$ roots of maxillary first molars, and the first and second molars generally exhibited types I and II, in contrast to the present results. Furthermore, these authors found a case of morphological type VIII in an $\mathrm{MB}$ root, as also reported by a study [24]. Similar results were observed in the present study.

A retrospective study [25] evaluated the root canal morphology of maxillary first and second molars by CBCT in a Turkish population. Using the classification of Vertucci [15], the most common morphological types in MB roots were types I and II, followed by type IV. The root canal configuration of 60 maxillary first molars in the Khasi population of Meghalaya using canal staining and a clearing technique was investigated and obtained results similar [26] to those of the present study in which type IV was the most prevalent in the $\mathrm{MB}$ root.

The prevalence of MB2 canals in maxillary molars was high in the present study, irrespective of sex, age group, or side of the arch evaluated $(p>0.05)$. Aydin [16] evaluated 402 CBCT scans of the maxillary first and second molars in a Turkish population and detected MB2 canals in $79.34 \%$ and $53.14 \%$ of cases, respectively. In a CBCT study of the root canal morphology of maxillary molars in a Chinese subpopulation, MB2 canals were detected in the first molars of $68.3 \%$ of cases and in the second molars of $23.8 \%$. The authors also found that when MB2 was present, Vertucci type IV was the most common morphology [27], in agreement with the results of the present study. MB2 canals in the maxillary first molar of $46 \%$ of cases and in the maxillary second molars of $14 \%$ were detected and the authors identified Vertucci type IV morphology as the most prevalent [28]. Authors evaluated 509 maxillary first and second molars by CBCT in a Chinese subpopulation and observed that when MB2 was present, type IV was the most common configuration in first molars, followed by types V and II [29]. The root canal morphology of maxillary first and second molars by CBCT in an Indian population was investigated, and morphological type IV was present in $50 \%$ and $38.6 \%$ of first and second molars with MB2 canals, respectively [30]. These results agree with the present study in which type IV was the most prevalent in MB roots, in addition to a high incidence of this fourth canal. 
In another study [29], Vertucci [15] type I was the most prevalent morphological configuration in $\mathrm{DB}$ and $\mathrm{P}$ roots of maxillary molars. Bhuyan et al. [26] found type I, followed by types II and V, to be the most common morphology in DB roots and type I followed by type II in $P$ roots. A total of 250 first and second molars extracted from an Iranian population by CBCT were evaluated and observed that Vertucci [15] type I was the most prevalent in $\mathrm{DB}$ and $\mathrm{P}$ roots [31]. These findings disagree with the results of the present study that showed greater morphological variations in these roots. Racial divergence may explain these variations.

In a case series in which five teeth, maxillary first and second molars, with bifurcated palatal canals were identified, the authors highlighted that the assumption of a single canal in all palatal roots of maxillary molars needs to be changed [32]. Within this context, a study [33] identified five cases of second molars with two or three canals in the palatal root. The findings of the present study corroborate the results of these authors since variations were observed in the morphology of the palatal canal, especially when the classification proposed by Vertucci [15] was used.

We found no significant differences in the prevalence of the different morphological canal types between sexes. Similar results have been reported by $[22,25,34]$. Regarding patient age, there were no significant differences between the predefined age groups [34].

Further studies investigating the root canal morphology of permanent maxillary molars are needed because of the complexity and different anatomical configurations of these teeth $[3,4]$ Knowledge of these configurations is essential to identify and treat additional canals and to increase the chances of successful endodontic treatment $[4,8,10]$.

\section{Conclusions}

There were no differences in the distribution of the different morphological canal types in permanent maxillary molars evaluated by CBCT according to sex, predefined age group, or position in the dental arch of the patients. MB2 canals were identified in $68.4 \%$ of the teeth evaluated.

\section{Data Availability}

No data were used to support this study.

\section{Conflicts of Interest}

The authors declare that there are no conflicts of interest.

\section{Authors' Contributions}

All the authors conceptualized the study, performed formal analysis, were involved in methodology formation, administrated the project, gathered resources, developed software, supervised the study, cured, investigated, validated, and visualized the data, wrote the original draft, and reviewed and edited the manuscript.

\section{Acknowledgments}

The authors thank the Coordination for the Improvement of Higher Education Personnel, Brazil (CAPES, Financing Code 001), and National Council for Scientific and Technological Development, Brazil (CNPq), for providing support to conduct this study.

\section{References}

[1] M. Torabinejad, D. Kutsenko, T. K. Machnick, A. Ismail, and C. W. Newton, "Levels of evidence for the outcome of nonsurgical endodontic treatment," Journal of Endodontics, vol. 31, no. 9, pp. 637-646, 2005.

[2] B. Willershausen, A. Kasaj, B. Röhrig, and B. B. Marroquin, "Radiographic investigation of frequency and location of root canal curvatures in human mandibular anterior incisors in vitro," Journal of Endodontics, vol. 34, no. 2, pp. 152-156, 2008.

[3] S. Razumova, A. Brago, H. Barakat, and A. Howijieh, Morphology of Root Canal System of Maxillary and Mandibular Molars Human Teeth - Key Skills and Clinical Illustrations 2019, pp. 01-31, Human, Moscow, Russia, 2019.

[4] Q.-H. Zheng, Y. Wang, X.-D. Zhou, Q. Wang, G.-N. Zheng, and D.-M. Huang, "A cone-beam computed tomography study of maxillary first permanent molar root and canal morphology in a Chinese population," Journal of Endodontics, vol. 36, no. 9, pp. 1480-1484, 2010.

[5] F. J. Vertucci, "Root canal morphology and its relationship to endodontic procedures," Endodontic Topics, vol. 10, no. 1, pp. 3-29, 2005.

[6] G. Hartwell, C. M. Appelstein, W. W. Lyons, and M. E. Guzek, "The incidence of four canals in maxillary first molars," The Journal of the American Dental Association, vol. 138, no. 10, pp. 1344-1346, 2007.

[7] J. D. Pécora, M. D. Sousa Neto, P. C. Saquy, and J. B. Woelfel, "In vitro study of root canal anatomy of maxillary second premolars," Brazilian Dental Journal, vol. 3, no. 2, pp. 81-85, 1992.

[8] M. Miyashita, E. Kasahara, E. Yasuda, A. Yamamoto, and T. Sekizawa, "Root canal system of the mandibular incisor," Journal of Endodontics, vol. 23, no. 8, pp. 479-484, 1997.

[9] A. Tiku, R. Kalaskar, and S. Damle, "An unusual presentation of all the mandibular anterior teeth with two root canals - a case report," Journal of Indian Society of Pedodontics and Preventive Dentistry, vol. 23, no. 4, pp. 204-206, 2005.

[10] J. Y. Y. Pan, A. Parolia, S. R. Chuah, S. Bhatia, S. Mutalik, and A. Pau, "Root canal morphology of permanent teeth in a Malaysian subpopulation using cone-beam computed tomography," BMC Oral Health, vol. 19, no. 1, p. 14, 2019.

[11] C. Estrela, M. R. Bueno, B. C. Azevedo, J. R. Azevedo, and J. D. Pécora, "A new periapical index based on cone beam computed tomography," Journal of Endodontics, vol. 34, no. 11, pp. 1325-1331, 2008.

[12] S. Patel, "New dimensions in endodontic imaging: part 2. Cone beam computed tomography," International Endodontic Journal, vol. 42, no. 6, pp. 463-475, 2009.

[13] S. Patel, J. Brown, T. Pimentel, R. D. Kelly, F. Abella, and C. Durack, "Cone beam computed tomography in Endodontics - a review of the literature," International Endodontic Journal, vol. 52, no. 8, pp. 1138-1152, 2019.

[14] F. S. Weine, H. J. Healey, H. Gerstein, and L. Evanson, "Canal configuration in the mesiobuccal root of the maxillary first 
molar and its endodontic significance," Oral Surgery, Oral Medicine, Oral Pathology, vol. 28, no. 3, pp. 419-425, 1969.

[15] F. J. Vertucci, "Root canal anatomy of the human permanent teeth," Oral Surgery, Oral Medicine, Oral Pathology, vol. 58, no. 5, pp. 589-599, 1984.

[16] H. Aydin, "Analysis of root and canal morphology of fused and separate rooted maxillary molar teeth in Turkish population," Nigerian Journal of Clinical Practice, vol. 24, no. 3, pp. 435-442, 2021.

[17] M. Omergorduysus, M. Gorduysus, and S. Friedman, "Operating microscope improves negotiation of second mesiobuccal canals in maxillary molars," Journal of Endodontics, vol. 27 , no. 11 , pp. $683-686,2001$.

[18] J.-H. Lee, K.-D. Kim, J.-K. Lee et al., "Mesiobuccal root canal anatomy of Korean maxillary first and second molars by conebeam computed tomography," Oral Surgery, Oral Medicine, Oral Pathology, Oral Radiology \& Endodontics, vol. 111, no. 6, pp. 785-791, 2011.

[19] R. Normanweller, S. Niemczyk, and S. Kim, "Incidence and position of the canal isthmus. Part 1. Mesiobuccal root of the maxillary first molar," Journal of Endodontics, vol. 21, no. 7, pp. 380-383, 1995.

[20] G. E. Nikoloudaki, T. G. Kontogiannis, and N. P. Kerezoudis, "Evaluation of the root and canal morphology of maxillary permanent molars and the incidence of the second mesiobuccal root canal in Greek population using cone-beam computed tomography," The Open Dentistry Journal, vol. 9, no. Suppl 2 M3, pp. S267-S272, 2015.

[21] C. M. Rwenyonyi, A. M. Kutesa, L. M. Muwazi, and W. Buwembo, "Root and canal morphology of maxillary first and second permanent molar teeth in a Ugandan population," International Endodontic Journal, vol. 40, no. 9, pp. 679-683, 2007.

[22] S. Sert and G. Bayirli, "Evaluation of the root canal configurations of the mandibular and maxillary permanent teeth by gender in the Turkish population," Journal of Endodontics, vol. 30, no. 6, pp. 391-398, 2004.

[23] G. T. D. M. Candeiro, S. D. S. Gonçalves, L. L. D. A. Lopes et al., "Internal configuration of maxillary molars in a subpopulation of Brazil's Northeast region: a CBCT analysis," Brazilian Oral Research, vol. 33, p. 82, 2019.

[24] E. Ozcan, A. M. Aktan, and H. Ari, "A case report: unusual anatomy of maxillary second molar with 3 mesiobuccal canals," Oral Surgery, Oral Medicine, Oral Pathology, Oral Radiology, and Endodontics, vol. 107, pp. e43-e46, 2009.

[25] A. Kalender, B. Celikten, P. Tufenkci et al., "Cone beam computed tomography evaluation of maxillary molar root canal morphology in a Turkish Cypriot population," Biotechnology \& Biotechnological Equipment, vol. 30, no. 1, pp. 145-150, 2016.

[26] A. Bhuyan, R. Kataki, P. Phyllei, and G. Gill, "Root canal configuration of permanent maxillary first molar in Khasi population of Meghalaya: an in vitro study," Journal of Conservative Dentistry, vol. 17, no. 4, pp. 359-363, 2014.

[27] H. E. Wang, C. Bo-Wen, Y. Hai-Yue et al., "Evaluation of root and canal morphology of maxillary molars in a Southern Chinese subpopulation: a cone-beam computed tomographic study," International Journal of Clinical and Experimental Medicine, vol. 10, no. 4, pp. 7030-7039, 2017.

[28] Z. Ghoncheh, B. M Zade, and M.J Kharazifard, "Root morphology of the maxillary first and second molars in an Iranian population using cone beam computed tomography," Journal of Dentistry (Tehran, Iran), vol. 14, no. 3, pp. 115-122, 2017.
[29] R. Zhang, H. Yang, X. Yu, H. Wang, T. Hu, and P. M. H. Dummer, "Use of CBCT to identify the morphology of maxillary permanent molar teeth in a Chinese subpopulation," International Endodontic Journal, vol. 44, no. 2, pp. 162-169, 2011.

[30] P. Neelakantan, C. Subbarao, R. Ahuja, C. V. Subbarao, and J. L. Gutmann, "Cone-beam computed tomography study of root and canal morphology of maxillary first and second molars in an Indian population," Journal of Endodontics, vol. 36, no. 10, pp. 1622-1627, 2010.

[31] A. Rouhani, A. Bagherpour, M. Akbari, M. Azizi, A. Nejat, and N. Naghavi, "Cone-beam computed tomography evaluation of maxillary first and second molars in Iranian population: a morphological study," Iranian Endodontic Journal, vol. 9, no. 3, pp. 190-194, 2014.

[32] A. Nosrat, P. Verma, M. L. Hicks, S. C. Schneider, A. Behnia, and A. A. Azim, "Variations of palatal canal morphology in maxillary molars: a case series and literature review," Journal of Endodontics, vol. 43, no. 11, pp. 1888-1896, 2017.

[33] R. K. Scarparo, L. Pereira, D. Moro, G. Grundling, M. Gomes, and F. S. Grecca, "Morphologic variations of maxillary molars palatal root and the importance of its knowledge for endodontic practice: a case series," The Journal of Contemporary Dental Practice, vol. 12, no. 2, pp. 138-142, 2001.

[34] M. Naseri, Y. Safi, A. Akbarzadeh Baghban, A. Khayat, and L. Eftekhar, "Survey of anatomy and root canal morphology of maxillary first molars regarding age and gender in an Iranian population using cone-beam computed tomography," Iranian Endodontic Journal, vol. 11, no. 4, pp. 298-303, 2016. 